\title{
ZnO thin films by spray pyrolysis and its doping with Sb
}

\author{
Jesus A. Sandoval ${ }^{\mathrm{a}}$, Ana M. Arato ${ }^{\mathrm{b}}$, E. Perez-Tijerina ${ }^{\mathrm{c}}$, A. G. Castillo ${ }^{\mathrm{b}}$, T. K. Das Roy ${ }^{\mathrm{b}}$ and B. \\ Krishnan ${ }^{\text {b }}$ \\ ${ }^{a}$ Facultad de Ciencias Químicas, Universidad Autónoma de Nuevo León, San Nicolás de los Garza, Nuevo León, México \\ ${ }^{b}$ Facultad de Ingeniería Mecánica y Eléctrica, Universidad Autónoma de Nuevo León, San Nicolás de los Garza, Nuevo León, México \\ ${ }^{c}$ Facultad de Física y Matemática, Universidad Autónoma de Nuevo León, San Nicolás de los Garza, Nuevo León, México \\ *E-mail: amarato2001@yahoo.com.mx
}

Recibido 20 de agosto de 2012, Aceptado 11 de septiembre de 2012

\begin{abstract}
Highly transparent $\mathrm{ZnO}$ thin films were prepared using spray pyrolysis of a solution containing $\mathrm{Zn}(\mathrm{OAc}) 2$ and $\mathrm{SbCl} 3$ on glass substrates kept at $400{ }^{\circ} \mathrm{C}$. Further, these films were doped with $\mathrm{Sb}$ by in situ process by dissolving $\mathrm{SbCl} 3$ in the spray solution. Crystallographic structural analysis was done using X-ray diffractometer and elemental analysis was done using Auger electron spectrometer. Morphological characterization was done by atomic force microscopy. The UV-Vis transmittance measurements indicated that the films were $90 \%$ transparent in the visible region. The value of band gap energy calculated from UV-Vis characterization showed that undoped and Sb doped films have slightly different band-gap energies. The electrical resistivity measurements showed a substantial change in the resistance of the $\mathrm{ZnO}$ thin films due to $\mathrm{Sb}$ doping.
\end{abstract}

Keywords: Spray pyrolysis, $\mathrm{ZnO}$, antimony doped $\mathrm{ZnO}$

\section{Introduction}

Zinc oxide $(\mathrm{ZnO})$ has been an extensively studied wide band gap semiconducting material [1]. $\mathrm{ZnO}$ in its bulk/thin film and nanostructure form have potential applications in LEDs, solar cells, flat panel displays and laser emission [1]. There are several reports, which describe the substantial changes in their electrical and optical properties due to doping. $\mathrm{N}$-type doping is relatively easy compared to $\mathrm{p}$-type doping for this material [1]. Doping with group III elements such as Al [2], Ga [3], and In [4] as substitutional elements of $\mathrm{Zn}$ by various methods were illustrated, and group VII elements such as $\mathrm{Cl}$ and I [5] were used as $\mathrm{O}$ substitutional elements to induce n-type conductivity. Spray pyrolysis is one of the low cost methods to prepare $\mathrm{ZnO}$ thin films with the added advantage of mixing the salt containing the dopant atoms with the precursor spray solution. $\mathrm{ZnO}$ thin films of $90-95 \%$ transmittance were deposited on glass substrate at $490{ }^{\circ} \mathrm{C}$ by spraying a solution containing zinc acetate [6]. At similar conditions, formation of polycrystalline $\mathrm{ZnO}$ thin films and a decrease in its resistivity with increase in substrate temperature were observed [7] Microstructural changes in $\mathrm{ZnO}$ thin films formed using zinc acetate precursor [8, 9] and detailed electrical characterization of were discussed [10]. Preparation of $\mathrm{ZnO}$ thin films using zinc chloride solution and their doping with $\mathrm{Sn}$ or/and $\mathrm{Al}$ were also reported [11-14]. Luminescent properties of sprayed $\mathrm{ZnO}$ and $\mathrm{ZnO}: \mathrm{In}$ thin films were investigated [15].
In the present work, we report the formation of $\mathrm{ZnO}$ thin films by spraying a solution containing $\mathrm{Zn}(\mathrm{OAc})_{2}$ on glass substrates at $400{ }^{\circ} \mathrm{C}$. Also, doping of these films with $\mathrm{Sb}$ by mixing $\mathrm{SbCl}_{3}$ with the precursor solution is achieved. The thin films obtained were polycrystalline with transmittance as high as $90 \%$ in the visible region. Analysis of X-ray diffraction patterns of the doped and undoped thin films showed the formation hexagonal $\mathrm{ZnO}$ phase. The elemental analysis by Auger spectroscopy indicated the presence of $\mathrm{Zn}, \mathrm{O}$ and $\mathrm{Sb}$ in these thin films. Evaluation of optical band gap from UV-Vis transmittance data showed that band gap value was slightly decreased with doping. The electrical resistivity measurements revealed a substantial change in the resistance of the $\mathrm{ZnO}$ thin films due to Sb doping.

\section{Experiment}

The chemical reactants used were zinc acetate (Fermont), $\mathrm{SbCl}_{3}$ (Fischer Scientific) and Ethanol (CTR). Substrates were corning glass slides. Compressed air was used as the carrier gas. For the preparation of $\mathrm{ZnO}$ thin films, zinc acetate salt was dissolved in minimum volume of water and then made up to $250 \mathrm{ml}$ by adding ethanol. Zn molarity was varied as 0.02 to 0.1 . The substrate temperature was $400{ }^{\circ} \mathrm{C}$. The thin films formed by spraying the solution containing $0.06 \mathrm{M}$ Zinc were selected for doping with $\mathrm{Sb}$. For doping, $\mathrm{SbCl}_{3}$ was dissolved in the precursor solution of $\mathrm{Zn}$ with stirring. The amount of $\mathrm{Sb}$ was varied as $2 \%, 4 \%$ and $6 \%$ of total $\mathrm{Zn}$ in the precursor solution. For the present 
study, $\mathrm{ZnO}: \mathrm{Sb}$ thin films formed with $2 \% \mathrm{Sb}$ were selected.

The thin films were characterized using various characterization techniques. X-ray diffraction patterns (XRD) of the thin films were recorded using Siemens D5000 diffractometer using $\mathrm{CuK}_{\alpha}$ radiation. The elemental analysis was done using Auger electron spectroscopy. The morphological studies were done using Atomic force microscopy (Q-Scope 3500) in contact mode. The optical absorbance of the films was measured using PerkinElmer UV-Vis spectrophotometer. Electrical resistivity measurements were carried using Keithley 6487 picoammeter/Voltage sourc e interfaced with a computer. The contacts used were two planar electrodes of $5 \mathrm{~mm}$ in length and $3 \mathrm{~mm}$ in separation using silver paint.

\section{Results and discussion}

$\mathrm{ZnO}$ thin films were formed by decomposition of zinc acetate on the substrates kept at $400{ }^{\circ} \mathrm{C}$. The thickness of the films was estimated as $\sim 150 \mathrm{~nm}$ by gravimetric method. Figure 1 shows the XRD patterns corresponding to the $\mathrm{ZnO}$ and $\mathrm{ZnO}: \mathrm{Sb}$ thin films. Standard diffraction pattern (PDF \#36-1451) for hexagonal $\mathrm{ZnO}$ is also given in the figure for comparison. In the pattern corresponding to $\mathrm{ZnO}$ film, all the peaks are coinciding with the standard lines. The maximum intensity peak in the experimental pattern corresponds to (100) plane. In the case of Sb doped films, all the peaks match with that of the standard pattern. The maximum intensity, (101) peak, coincides with that of the standard (004) plane, which is parallel to (002) is also present in the doped films. No peak corresponding to $\mathrm{Sb}_{2} \mathrm{O}_{3}$ is observed in the pattern. Sb doping in $\mathrm{ZnO}$ thin films retained its hexagonal structure except induced growth of (004) plane suppressing the (112) plane. From the width of the peaks, average particle size was calculated for both the doped and the undoped thin films using Debye-Scherrer's formula. The values were $14 \mathrm{~nm}$ and $11 \mathrm{~nm}$ respectively. Thus, $\mathrm{Sb}$ doping slightly increased the particle size.

Auger electron survey of $\mathrm{Zn}: \mathrm{Sb}$ thin film without surface etching is given in figure 2 . The presence of $\mathrm{Zn}, \mathrm{O}$ and $\mathrm{Sb}$ are indicated. These elements are identified by their major Auger peaks corresponding the transitions viz; Zn1(ZnLMM), O1(KLL), $\mathrm{Sb} 1(\mathrm{MNN})$. A weak signal of $\mathrm{C}$ noted as $\mathrm{C} 1$ corresponding to (C(KLL) transition is also marked in the figure. This can be from zinc acetate or from surface impurity. Approximate quantification is done using the differential peak strength and the sensitivity factors for corresponding elements. The percentages are 49.3, 33, 5.7 and 12 respectively for $\mathrm{Zn}, \mathrm{O}, \mathrm{Sb}$ and $\mathrm{C}$.

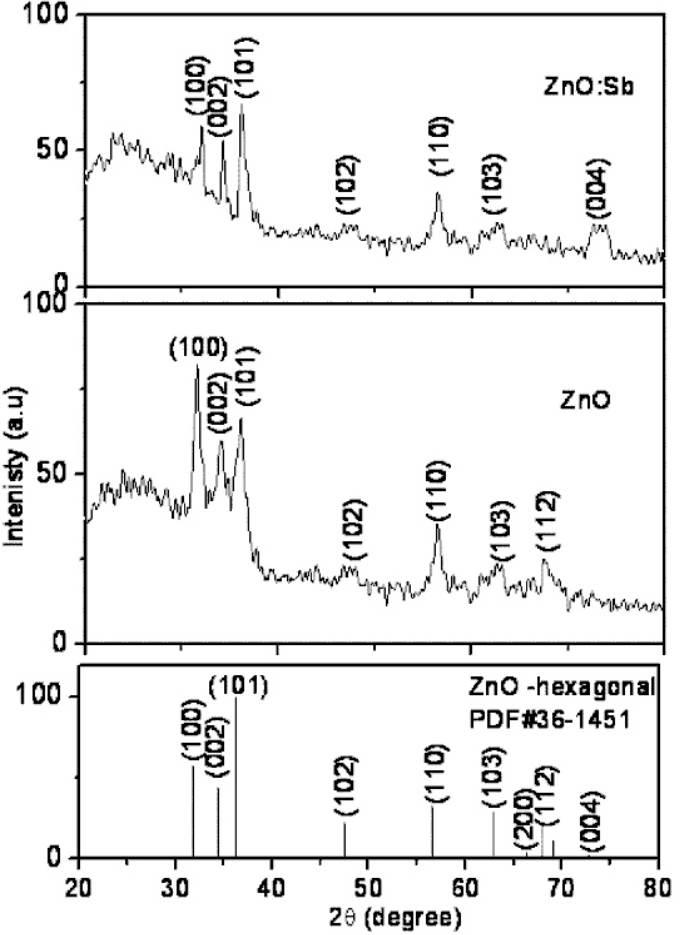

Figure 1. $\mathrm{XRD}$ patterns of $\mathrm{ZnO}$ and $\mathrm{ZnO}: \mathrm{Sb}$ thin films

Morphological features of the doped and undoped films are given in the atomic force micrographs, figure 3. Nearly spherical grains are seen in both cases. In undoped thin films pinholes are present as observed in figure 3(a). However, the formation of pinholes is reduced by $\mathrm{Sb}$ doping as seen in figure 3(b). At the same time, there is a slight increase in the grain size due to doping which is in agreement with the XRD results.

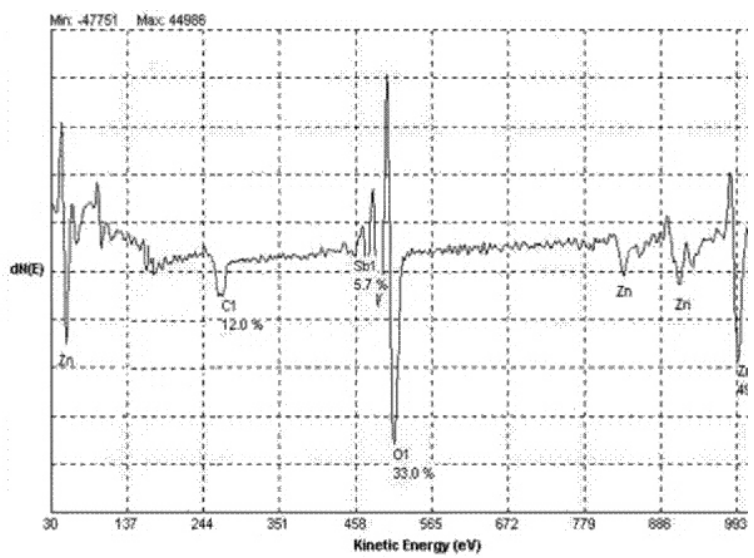

Figure 2. Auger survey for $\mathrm{ZnO}: \mathrm{Sb}$ thin films 


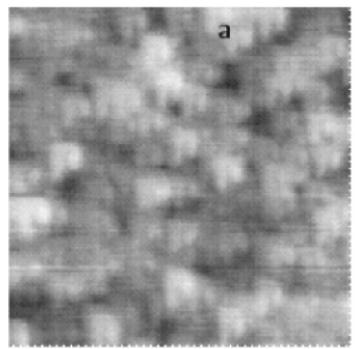

$5 \mu \mathrm{m}$

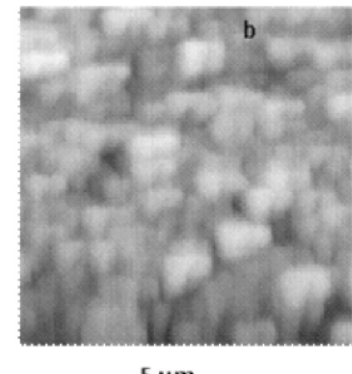

$5 \mu \mathrm{m}$
Figure 3. Atomic force micrographs for (a) $\mathrm{ZnO}$ and (b) $\mathrm{ZnO}: \mathrm{Sb}$ thin films

Figure 4(a) shows optical transmittance (T) spectra of the doped and undoped films in the wavelength range of $350-900 \mathrm{~nm}$. From the curves, nearly $90 \%$ transmittance is observed in the case of undoped $\mathrm{ZnO}$ films. Due to doping transmittance is reduced to $80 \%$. From the spectral data, absorption spectra for both the films were generated using equation 1 .

$$
\alpha=\frac{1}{\mathrm{t}} \ln \frac{1}{T}
$$

where, $\alpha$ is the absorption coefficient and $t$ is the thickness of the film. From the spectra, the optical band gap of the thin films due to band-band transition is determined using the empirical relation (equation 2).

$$
(\alpha h v)^{n}=A\left(h v-E_{g}\right)
$$

where $E_{g}$ is the optical band gap and $\mathrm{n}=2,1 / 2$, $2 / 3$ respectively for allowed direct, allowed indirect and forbidden direct transitions and $\mathrm{A}$ is a constant. We have chosen $\mathrm{n}=2$ which gives a good linear fit in the plot of $(\alpha h v)^{2}$ vs $h v$ as shown in figure 4 (b). The band gap values for the doped and undoped films are indicated in the figure and the respective values are $3.24 \mathrm{eV}$ and $3.29 \mathrm{eV}$. The slight decrease in $E_{g}$ can be attributed to the small increase in grain size for the $\mathrm{Sb}$ doped $\mathrm{ZnO}$ film. This result is in accordance with XRD analysis.

The electrical resistivity of the $\mathrm{ZnO}$ and $\mathrm{ZnO}: \mathrm{Sb}$ thin films are evaluated from I-V characteristics of the films given in figure 5(a) and (b). The resistance (R) values were evaluated from the slope of the straight line graphs. By knowing the thickness (150 $\mathrm{nm})$, the corresponding resistivity values were estimated. The values are of the order of $10^{2} \Omega \mathrm{cm}$ and $10^{7} \Omega \mathrm{cm}$ for $\mathrm{ZnO}: \mathrm{Sb}$ and $\mathrm{ZnO}$ thin films respectively as indicated in the figure.
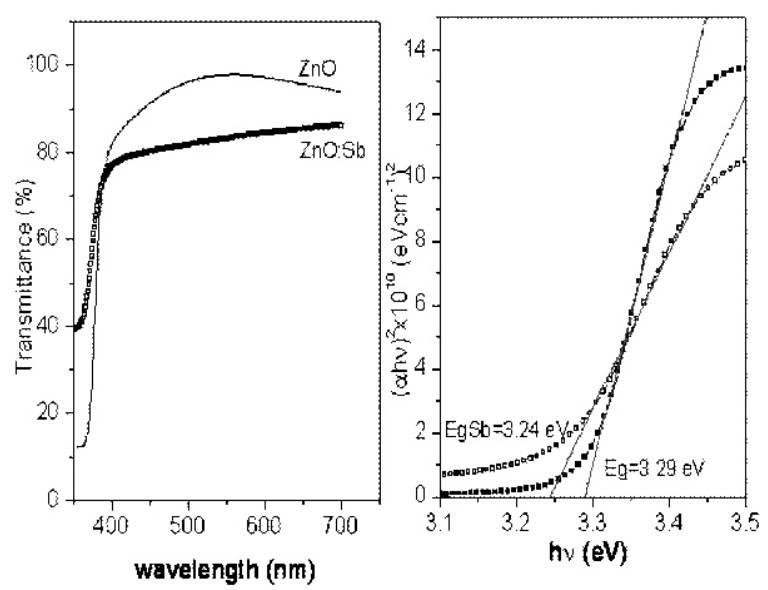

Figure 4. (a) Transmittance spectra (b) Evaluation of Eg for $\mathrm{ZnO}$ and $\mathrm{ZnO}: \mathrm{Sb}$ thin films

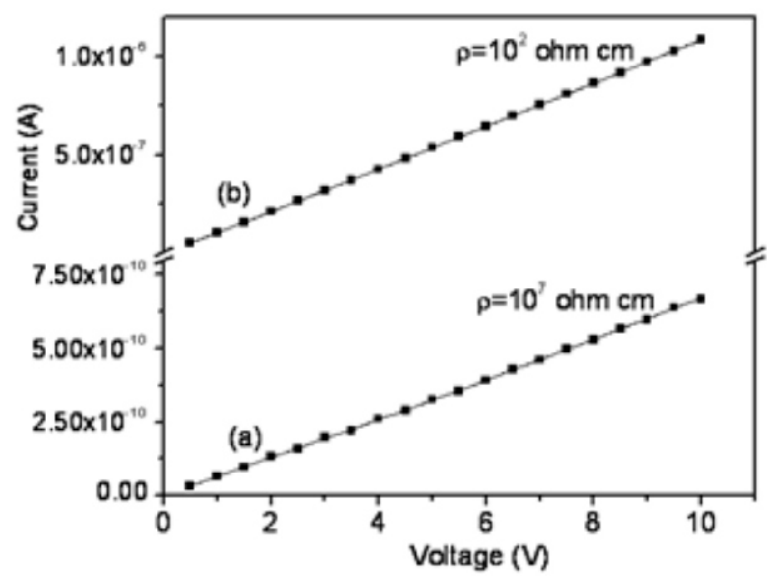

Figure 5. I-V characteristics for (a) $\mathrm{ZnO}$ and (b) $\mathrm{ZnO}: \mathrm{Sb}$ thin films

Thus resistivity value of $\mathrm{ZnO}$ is significantly reduced by doping with $2 \% \mathrm{Sb}$. By hot-probe technique, the doped films are found to be n-type. It was reported [1] that $\mathrm{ZnO}$ is naturally p-type semiconductor because of $\mathrm{Zn}$ interstitials or $\mathrm{O}$ vacancies. In the present case, the as-prepared $\mathrm{ZnO}$ films are nearly intrinsic. Doping of $\mathrm{ZnO}$ thin films with metals having higher valencies such as $\mathrm{Al}, \mathrm{Ga}$, In created shallow zinc substitutional defects [1-4] to form highly conducting films after doping. Hence, in the case of $\mathrm{ZnO}: \mathrm{Sb}$, the reduced resistivity can be attributed for the presence of substitutional defects of $\mathrm{Sb}_{\mathrm{Zn}}$.

\section{Conclusions}

$\mathrm{ZnO}$ thin films were prepared by spray pyrolysis using a solution of $\mathrm{Zn}(\mathrm{OAc})_{2}$ on glass substrates at $400{ }^{\circ} \mathrm{C}$. Also, $\mathrm{ZnO}: \mathrm{Sb}$ thin films were obtained by 
mixing $\mathrm{SbCl}_{3}$ with the precursor solution for $\mathrm{ZnO}$. The $\mathrm{ZnO}$ thin films formed were polycrystalline hexagonal structure with $90 \%$ transmittance in the visible region. After doping, the transmittance was reduced to $80 \%$. Auger spectroscopic analysis indicated the presence of $\mathrm{Zn}, \mathrm{O}$ and $\mathrm{Sb}$ in these films. Optical band gap values were evaluated from UV-Vis transmittance data showed that band gap value for doped films was slightly lower than that of the undoped films. The electrical resistivity measurements showed a substantial change in the resistance of the $\mathrm{ZnO}$ thin films due to $\mathrm{Sb}$ doping. Thus $\mathrm{Sb}$ is a effective dopant for $\mathrm{ZnO}$ thin film which will be useful for various optoelectronic devices.

\section{Acknowledgments}

The authors are thankful to PAICYT, UANL, NL, Mexico and SEP -CONACYT- Mexico, PROMEPMexico for the financial assistance, Anabel Alvarez, Ciencias Químicas, UANL, NL, Mexico, for recording of XRD.

\section{References}

1. Ozgur, U.; Alivov, Ya. I.; Liu, C.; Teke, A.; Reshchikov, M. A.; Dogan, S.; Avrutin, V.; Cho, S. J.; Morkoc, H. J. Appl. Phys. 2005 98, 041301.

2. Cooray, N. F.; Kushiya, K.; Fujimaki, A.; Okumura, D.; Sato, M.; Ooshita, M.; Yamase, O. J. Appl. Phys. 1999, 38, 6213.

3. Olvera de la L, M.; Maldonado, A. Phys. Status Solidi A. 2003, 196, 410.

4. Zironi, E. P.; Canetas-Ortega, J.; Gomez, H.; Maldonado, A.; Asomosa, R.; Palacios-Gomez, J. Thin Solid Films 1997, 293, 117.

5. Kato, H.; Sano, M.; Miyamoto, K.; Yao, T. J. Cryst. Growth. 2002, 538, 237-239

6. Peredins, D.; Gauckler, L. J. J. Electroceramics 2005, 14, 103.

7. Ashour, A.; Kaid, M. A.; El-Sayed, N. Z.; Ibrahim, A. A. Appl. Surf. Sci. 2006, 252, 7844.

8. Paraguay D., F.; Estrada L., W.; Acosta N., D. R.; Andrade, E.; Miki-Yoshida, M. Thin Solid Films 1999, 350, 192.

9. Van Heerden, J. L.; Swanepoel, R. Thin Solid Films 1997, $299,72$.

10. R. Ayouchi, D. Leinen, F. Martin, M. Gabas, E. Dalchiele, J. R. Ramos-Barrado, Thin Solid Films 2003, 426, 68.

11. Allah, F. K.; Abe, S. Y.; Nunez, C. M. ; Khelil, A. ; Cattin, L.; Morsli, M.; Bernede, J. C.; Bougrine, A.; del Valle, M. A.; Diaz, F. R. Appl. Surf. Sci. 2007, 23, 9241.

12. Mohammad, M. T.; Hashim, A. A.; Al-Maamory, M. H. Mater. Chem. Phys. 2006, 99, 382.

13. Ben Achour, Z.; Ktari, T.; Ouertani, B.; Touayar, O.; Bessais, B.; Ben Brahim, J. Sens. Actuators, A 2007, 134, 447.

14. Bougrine, A.; El Hichou, A.; Addou, M.; Ebothe, J.; Kachouane, A.; Troyon, M. Mater. Chem. Phys. 2003, 80, 438.

15. Kumar, P. M. R.; Kartha, C. S.; Vijayakumar, K. P.; Abe, T.; Kashiwaba, Y.; Singh, F.; Avasthi, D. K. Semicond. Sci. Technol. 2005, 20, 120. 